\title{
Uma análise descritivo-comparativa de duas traduções para o português brasileiro da obra Death of a Salesman
}

\section{A descriptive-comparative analysis of two translations into Brazilian Portuguese of Death of a Salesman}

\author{
Maria Clara Nogueira Zacarin* \\ Virgínia Fernandes Radighieri* \\ Valéria Biondo ${ }^{* * *}$
}

Resumo: Este estudo tem por objetivo analisar e comparar duas traduções para o português brasileiro da peça Death of a Salesman, do escritor americano Arthur Miller, a fim de discutir os processos tradutórios utilizados por cada tradutor e 0 modo como a interpretação pessoal de cada um interfere no resultado final do texto traduzido. Para tanto, será realizada uma pesquisa de cunho qualitativo comparando trechos das traduções de José Rubens Siqueira e Flávio Rangel, de acordo com os procedimentos técnicos definidos por Barbosa (1990). Espera-se comprovar que cada tradutor interfere no resultado final segundo seus conhecimentos e sua visão de

" Graduanda pela Universidade do Sagrado Coração (USC).

"* Graduanda pela Universidade do Sagrado Coração (USC).

**** Docente da Universidade do Sagrado Coração (USC). 
mundo. Buscamos, com esse estudo, apontar a importância do tradutor, além de demonstrar a necessidade de estudos comparativos.

Palavras-chave: tradução literária; análise descritivo-comparativa; procedimentos tradutórios; Death of a Salesman.

Abstract: This study aims to analyze and compare two translations of Arthur Miller's play Death of a Salesman to the Brazilian Portuguese, in order to discuss the translation procedures used by each translator, and how each personal interpretation interferes in the final result of the translated text. So, a qualitative research was carried out in order to compare excerpts of both José Rubens Siqueira's and Flávio Rangel's translations, according to the technical translation procedures defined by Barbosa (1990). With this study, we hope to vouch that each translator interferes in the final result, according to his knowledge and his vision of the world. We look to point out the importance of the translator and the necessity of comparative studies.

Keywords: Literary Translation; descriptive-comparative analysis; translation procedures; Death of a Salesman. 
ZACARIN, M. C. N.; RADIGHIERI, V. F.; BIONDO, V. - Uma análise descritivo-comparativa de duas versões para o português brasileiro da obra Death of a Salesman

A coisa mais indispensável a um homem é reconhecer o uso que deve fazer do seu próprio conhecimento.

Platão

\section{Introdução}

A literatura é um dos elementos mais importantes de qualquer cultura. Mas além de fazer parte de uma cultura específica, ela pode permear várias outras e ser compartilhada com culturas totalmente diferentes. Entretanto, para que haja essa "viagem" da literatura, é necessário alguém que faça a transição entre as línguas e as culturas. Esse alguém é o tradutor. 0 tradutor, além de ser aquele que realiza a tradução em si, também é quem transpõe as culturas. Em entrevista, a tradutora Lia Wyler diz que "a tradução é uma ponte entre duas culturas" (ANAUATE 2007); já para Arrojo (1986: 12) “o processo de tradução (funciona) como transporte de significados entre língua A e língua B.".

A tradução é o que possibilita à literatura "viajar" pelo mundo, tendo sua história e sua cultura compartilhadas em diversas nações, permitindo-nos o acesso ao conhecimento do contexto histórico-cultural em que se insere. Como foi definido acima, a tradução não é somente uma transposição de significados de uma língua-fonte a uma língua-alvo; ela envolve habilidades muito maiores. É necessário que haja a interpretação do texto original, sua releitura e reescrita na nova língua. Por essa razão, há várias possibilidades de tradução para uma única obra e ainda assim todas podem ser corretas.

Em vista da importância e da abrangência da literatura é que propomos um estudo para mostrar como é feito o processo da tradução de um livro. A obra escolhida para análise é Death of a Salesman, de Arthur Miller, que possui duas traduções para a Língua Portuguesa do Brasil, sendo elas A morte do caixeiro viajante, traduzida por Flávio Rangel, distribuída pela editora Abril S.A. Cultural e Industrial, publicada no ano de 1976, e A morte de um 
ZACARIN, M. C. N.; RADIGHIERI, V. F.; BIONDO, V. - Uma análise descritivo-comparativa de duas versões para o português brasileiro da obra Death of a Salesman

caixeiro-viajante, traduzida por José Rubens Siqueira, distribuída pela Companhia das Letras, publicada em 2009.

Arthur Miller (1915-2005) foi um dramaturgo norte-americano nascido na cidade de Nova York e um dos principais autores do teatro norte-americano contemporâneo, sendo algumas de suas obras mais importantes e famosas Death of a Salesman e The Crucible.

Este estudo tem como objetivo analisar as duas traduções da primeira, Death of a Salesman, e averiguar as escolhas léxico-semânticas da língua alvo para a manutenção do sentido cultural e crítico presente na obra original, a fim de encontrar similaridades e discrepâncias.

No desenvolvimento deste trabalho, temos como objetivo principal a caracterização dos procedimentos técnicos e escolhas tradutórias de José Rubens Siqueira e Flávio Rangel no processo de tradução literária da obra. Para isso, buscaremos responder às seguintes questões: quais os procedimentos técnicos utilizados na tradução; qual versão se mostra mais adequada em vista do original e por quê?

Este trabalho se justifica por suas tentativas de mostrar que um texto possui mais de uma possibilidade de tradução correta, de demonstrar as diferentes estratégias tradutórias que podem ser utilizadas em um mesmo texto e de averiguar a interpretação de cada tradutor para a mesma obra.

\section{A peça e suas traduções para o português}

A análise será baseada na peça Death of a Salesman, de Arthur Miller, um dos clássicos da literatura dramática do século 20, a qual retrata o momento histórico da busca pelo american dream (sonho americano), sem uma visão romantizada; ao contrário, mostra o drama e a tragédia na busca 
ZACARIN, M. C. N.; RADIGHIERI, V. F.; BIONDO, V. - Uma análise descritivo-comparativa de duas versões para o português brasileiro da obra Death of a Salesman

por tal sonho - que não era tão perfeito como se idealizava e nem acessível a todos -, criticando essa ilusão dos Estados Unidos como um país perfeito.

Tal livro é o mais famoso de Miller, foi traduzido para 29 línguas, sendo uma delas o português (tanto brasileiro quanto de Portugal), com o título em duas diferentes traduções: A morte de um caixeiro-viajante, de José Rubens Siqueira, a publicação mais recente (2009), e A morte do caixeiro viajante, de Flávio Rangel (1976).

A publicação mais antiga possui 205 páginas, contendo uma introdução de 20 páginas sobre o autor, o contexto histórico e a peça no teatro dos anos 1950. A diagramação do livro segue padrões amplamente disseminados e difundidos para textos dramatúrgicos em geral, com o nome dos personagens em caixa alta na primeira linha e suas respectivas falas nas linhas a seguir. As rubricas são sinalizadas pelo itálico e entre parênteses.

A publicação mais recente possui 461 páginas, intitulada $A$ morte de um caixeiro-viajante e outras 4 peças de Arthur Miller, sendo essas peças: $O$ homem de sorte, Todos eram meus filhos, As bruxas de Salém e Um panorama visto da ponte, todas também traduzidas por José Rubens Siqueira. Antes do início das versões há um prefácio escrito por Otavio Frias Filho contextualizando-as e comentando sobre o sonho americano. A diagramação do livro tem estilo literário, com o nome dos personagens também em caixa alta e as marcações das rubricas em itálico e entre parênteses, porém com as falas dos personagens à frente de seus respectivos nomes, e não embaixo, como na publicação citada anteriormente.

Death of a Salesman foi o livro escolhido para análise devido a sua importância e influência na cultura norte-americana, tendo se expandido para outros países, até chegar ao Brasil, possibilitando que leitores estrangeiros tivessem conhecimento do contexto histórico da época e da literatura de Arthur Miller. Além disso, a tradução literária impõe muitos desafios para o tradutor, pois, segundo Lawrence Venuti, 
ZACARIN, M. C. N.; RADIGHIERI, V. F.; BIONDO, V. - Uma análise descritivo-comparativa de duas versões para o português brasileiro da obra Death of a Salesman

um texto literário nunca pode simplesmente expressar o significado pretendido pelo autor num estilo pessoal. 0 texto, ao contrário, coloca em funcionamento as formas coletivas nas quais o autor pode, de fato, ter um investimento psicológico, mas que, por sua própria natureza, despersonaliza e desestabiliza o significado. (VENUTI 2002: 25)

\subsection{0 autor}

Arthur Asher Miller foi um dramaturgo norte-americano nascido na cidade Nova York no bairro do Harlem em 17 de outubro de 1915, filho de um casal de imigrantes judeus da Polônia, e um dos principais autores do teatro norte-americano contemporâneo, sendo algumas de suas obras mais importantes e famosas Death of a Salesman e The Crucible, pelas quais ele é mais conhecido. Foi ganhador de diversos e importantes prêmios como o Pulitzer de Teatro (1949), o Tony - por três vezes -, o Círculo de Críticos de Teatro de Nova lorque (1949), o Príncipe das Astúrias de Letras (2002) e o Jerusalém (2003).

Miller se formou em jornalismo no ano de 1940, depois transferiu o curso para Inglês na Universidade de Michigan. Durante sua graduação, escreveu uma primeira peça, No Villain, pela qual ganhou o Prêmio Hopwood, trazendo reconhecimento a ele e a possibilidade de se tornar um dramaturgo. Sua segunda peça foi Honors at Dawn, que também ganhou o Prêmio Hopwood.

Em 1940, sua primeira peça para o teatro foi produzida, nomeada The Man Who Had All The Luck; no entanto, foi um fracasso, sendo encerrada após quatro apresentações e tendo péssimas críticas, apesar de ter ganhado o prêmio Theatre Guild's National Award. Em contrapartida, sua peça seguinte, All My Sons, foi um sucesso em 1947, sendo apresentada por quase um ano inteiro na Broadway, rendendo a Miller o seu primeiro Prêmio Tony por Melhor Autor. 
ZACARIN, M. C. N.; RADIGHIERI, V. F.; BIONDO, V. - Uma análise descritivo-comparativa de duas versões para o português brasileiro da obra Death of a Salesman

Após tal sucesso, a carreira de Arthur Miller deslanchou e o mesmo foi consagrado como um dos maiores autores americanos de sua época. Ao longo de sua trajetória, escreveu vinte peças, seis delas em ato único, quatro roteiros de cinema, uma autobiografia, cinco reportagens, cinco livros de ficção, entre outros. É interessante ressaltar que a obra analisada neste trabalho, Death of a Salesman, teve seu primeiro ato escrito em menos de um dia.

As peças de Miller registram o impacto produzido na esfera ética pelas grandes crises históricas de sua época, como a Depressão econômica que se seguiu à quebra da bolsa de 1929, a ascensão do nazismo, a experiência aterradora do Holocausto, o macarthismo, a política de delações instituída pelo governo federal norte-americano durante a guerra fria e a caça aos comunistas, além da ideologia inerente ao chamado "Sonho americano" de sucesso pessoal e material. Representar dramaturgicamente toda essa gama de assuntos foi um desafio constante para ele, e envolveu o uso de diferentes recursos expressivos, além da crítica contínua do pensamento dominante, engendrado pela máquina estatal e pela indústria do consumo. Dentre todos os intelectuais que manifestaram publicamente seu repúdio ao macarthismo e à política persecutória dos anos 1940 e 1950, Miller foi a figura de maior notoriedade. Nas décadas de 1960 e 1970 ele teve participação ativa no movimento de luta pelos direitos civis e na campanha de protesto contra a guerra do Vietnã, e em 2003 manifestou sua crítica irrestrita à política externa de George W. Bush e à invasão do Iraque pelos Estados Unidos. A história do engajamento político de Miller mescla-se à sua própria vida como dramaturgo.

\subsection{Os tradutores}

José Rubens Siqueira de Madureira, nascido em 20 de outubro de 1945 em Sorocaba/SP é ator, dramaturgo, cenógrafo, figurinista e diretor. 
ZACARIN, M. C. N.; RADIGHIERI, V. F.; BIONDO, V. - Uma análise descritivo-comparativa de duas versões para o português brasileiro da obra Death of a Salesman

Trabalhou com cinema de animação nos anos 1960, e integrou a equipe do Teatro de Arena. Durante as décadas de 1960 e 1970, seus filmes de animação representaram o Brasil em Festivais de Cinema na Alemanha, Teerã, Uzbequistão e Cazaquistão e também na antiga União Soviética. No Brasil, ganhou diversos prêmios nos Festivais de Cinema de Gramado, Brasília e Belém.

Flávio Nogueira Rangel nasceu em 6 de agosto de 1934 em Tabapuã/SP. É um dos maiores nomes do teatro brasileiro além de autor, jornalista e tradutor de peças teatrais. Participou de várias montagens do Teatro Brasileiro de Comédia, companhia que revitalizou e modernizou o teatro na década de 50 no Brasil. Dirigiu mais de oitenta peças, traduziu dezenove, além de produzir e escrever para o teatro. Ajudou na preparação de cinco livros, colaborando com os principais órgãos de imprensa do país, além de dirigir shows musicais de Simone, Nara Leão, Raíces de América.

\section{Tradução e competências do tradutor}

Neste estudo, será trabalhada a tradução literária, um dos gêneros mais comuns e abrangentes da tradução. Como será discutido adiante, o processo de tradução de uma obra teatral exige uma atenção especial aos diversos elementos que a compreendem, como o contexto, a linguagem, a cultura em que está inserida, entre outros.

Ao contrário da tradução de textos ficcionais e poéticos, que se realiza integralmente no plano da expressão literária, a tradução de textos dramatúrgicos pressupõe a adequação entre o conjunto de sentidos expressos na obra e as condições fonéticas, sintáticas e prosódicas da sua enunciação em cena. Mesmo se pensado em termos de "literatura dramática", o texto teatral diferencia-se do literário pelo fato de não prescindir de uma dimensão 
ZACARIN, M. C. N.; RADIGHIERI, V. F.; BIONDO, V. - Uma análise descritivo-comparativa de duas versões para o português brasileiro da obra Death of a Salesman

cênica, ainda que esta seja apenas imaginada por um potencial leitor no ato da leitura silenciosa e individual.

Ao contrário do texto literário, o texto dramatúrgico presumivelmente poderá, em algum momento, ganhar voz em cena, e esta, portanto, apresenta-se como uma referência importante e como um foco de atenção necessário para o trabalho tradutório.

Por essa razão, Rónai (1987, p. 23) declara que "o tradutor deve conhecer todas as minúcias semelhantes da língua de seu original a fim de captar, além do conteúdo estritamente lógico, o tom exato, os efeitos indiretos, as intenções ocultas do autor". Em conformidade com tal pensamento, Venuti (2002) afirma que:

a língua nunca é simplesmente um instrumento de comunicação, empregado por um indivíduo de acordo com um sistema de regras mesmo que a comunicação esteja, sem dúvida, entre funções realizáveis pela linguagem. Seguindo Deleuze e Guattari (1987), vejo a língua como uma força coletiva, um conjunto de formas que constituem um regime semiótico. (VENUTI 2002: 24)

Segundo Pagano, a tradução é definida como "um processo interpretativo e comunicativo que consiste na reformulação de um texto com os meios de outra língua e que se desenvolve em um contexto social e com uma finalidade determinada" (HURTADO 2001: 1 apud PAGANO 2005: 27).

Visto que a tradução não é um processo simples, mas sim complexo e meticuloso, é necessário que a pessoa responsável por fazê-la, no caso, o tradutor, disponha de certas competências tradutórias, como é mencionado por Pagano (2005: 15): “a competência tradutória é um conhecimento especializado, integrado por um conjunto de conhecimentos e habilidades, que identifica o tradutor e o distingue de outros falantes bilíngues não tradutores". Dentre essas competências, incluem-se "conhecimentos linguísticos, textuais, temáticos, culturais, de documentação, capacidade de transferência, etc." (PAGano 2005: 23). 
ZACARIN, M. C. N.; RADIGHIERI, V. F.; BIONDO, V. - Uma análise descritivo-comparativa de duas versões para o português brasileiro da obra Death of a Salesman

Como mencionado acima, o conhecimento linguístico do par de línguas que será trabalhado é essencial para o desenvolvimento do processo tradutório, pois

um conhecimento apurado da gramática do par linguístico com que o tradutor trabalha é essencial para que ele possa desenvolver estratégias apropriadas de escolha dos recursos gramaticais que a língua de chegada lhe oferece para a reescrita dos recursos gramaticais da língua de partida. (MAGALHÃES in PAGANO et al. 2013: 102)

\section{Procedimentos técnicos da tradução literária}

Desde que existe a necessidade de comunicação entre duas línguas diferentes, há a necessidade de tradução. A partir disso, por milênios tem se discutido qual a melhor forma de se traduzir, principalmente quando falamos de tradução literária, pois ela exige maior competência e maior conhecimento dos diversos procedimentos tradutórios, como já foi dito por Barbosa: "considero a tradução como 'um fazer, um fazer intelectual que requer o domínio de operações mentais'” (BORDENAVE 1987:2 apud BARBOSA 1990).

Esses conhecimentos permeiam diversas áreas do conhecimento, dentre as quais a análise do discurso, a antropologia (ou linguística antropológica), a estética, a estilística, a filosofia (especificamente a da linguagem), a informática, a inteligência artificial, a lexicografia, a linguística, a lógica, a neurofisiologia, a psicolinguística, a psicologia cognitiva, a semiótica, a sociolinguística, a teoria da comunicação e a teoria literária (cf. ARROJo 1988; BASSNETT-MCGUIRE 1978; BORDENAVE 1988 apud BARBOSA 1990).

Para o desenvolvimento da análise e da discussão do trabalho, será utilizado como base teórica o livro Procedimentos técnicos da tradução, de 
ZACARIN, M. C. N.; RADIGHIERI, V. F.; BIONDO, V. - Uma análise descritivo-comparativa de duas versões para o português brasileiro da obra Death of a Salesman

Heloísa Gonçalves Barbosa, no qual a autora propõe treze parâmetros de procedimentos técnicos: tradução palavra-por-palavra, tradução literal, transposição, modulação, equivalência, omissão vs. explicitação, compensação, reconstrução de períodos, melhorias, transferência, explicação, decalque e adaptação.

Para conhecimento prévio, faremos uma breve exposição de tais procedimentos, por isso começaremos com os cinco primeiros. 0 "palavra-porpalavra" se trata da mera substituição de termos da língua-fonte para a língua-alvo, mantendo idênticas a semântica e a ordem sintática, ou o mais próximo possível. A "tradução literal" reproduz de perto a mensagem no âmbito semântico, porém se adequando às normas da língua-alvo. A "transposição" ocorre quando o termo traduzido muda de classe gramatical em relação àquele no qual estava na língua-fonte. A "modulação" sucede quando a mensagem na língua-fonte é reproduzida sob um outro ponto de vista na língua-alvo. A "equivalência" consiste em substituir uma frase da língua-fonte por uma de sentido correspondente na língua-alvo.

Seguindo com os próximos cinco procedimentos, a “omissão" diz respeito, como o próprio nome diz, ao ato de omitir uma informação considerada desnecessária ou redundante, enquanto que a "explicitação" é o oposto, nela há a adição de informação para a melhor compreensão da informação presente na língua-fonte. A “compensação” se dá quando um recurso estilístico utilizado na língua-fonte não cabe na língua-alvo, sendo assim, reproduz-se um recurso estilístico de efeito equivalente em outro ponto do texto traduzido. A "reconstrução de períodos", como o próprio nome já denuncia, é realizada quando uma frase da língua-fonte é reproduzida em outra ordem, para que soe mais natural na língua-alvo. As "melhorias" acontecem quando o texto original apresenta possíveis erros, dessa forma, o tradutor os corrige para tornar o texto traduzido mais adequado.

Por último temos: a "transferência", que sucede quando algum material textual da língua-fonte é inserido na língua-alvo, tem como 
ZACARIN, M. C. N.; RADIGHIERI, V. F.; BIONDO, V. - Uma análise descritivo-comparativa de duas versões para o português brasileiro da obra Death of a Salesman

subcategorias "estrangeirismo, estrangeirismo aclimatado, estrangeiro transliterado, estrangeirismo + explicação" (BARBOSA 1990). A “explicação” é quando um termo da língua-fonte é desconhecido pela cultura da língua de chegada, então o mesmo é substituído por uma explicação para facilitar a compreensão do leitor. O "decalque" consiste na tradução literal de sintagmas ou tipos frasais da língua-fonte, sendo muitas vezes interpretado como uma aclimatação do empréstimo linguístico. A "adaptação" é descrita como o "extremo" da tradução, quando a situação empregada na língua-fonte não existe ou não é compreendida na cultura da língua de chegada, em vista disso, uma situação de efeito equivalente é reproduzida na língua-alvo (BARBOSA 1990).

\section{Metodologia}

A metodologia adotada neste trabalho é de cunho qualitativo, visando comparar as traduções, examinando as escolhas tradutórias de ambos tradutores, com os objetivos específicos de ler e extrair trechos para análise das escolhas tradutórias de cada um; mostrar e comparar algumas das escolhas e estratégias tradutórias de José Rubens Siqueira e Flávio Rangel.

A forma de aplicação da metodologia será desenvolvida através da extração de trechos divergentes das duas traduções, colocando-os em tabelas para uma melhor visualização e comparação. Todos os verbetes mencionados na análise foram extraídos do dicionário Oxford Advanced Learner's Dictionary, exceto quando sinalizado, e as traduções dos mesmos foram elaboradas pelas autoras. Os trechos selecionados para análise neste trabalho foram escolhidos devido às divergências encontradas entre as traduções, em se considerando aspectos linguísticos, culturais, semânticos e, no caso do 
ZACARIN, M. C. N.; RADIGHIERI, V. F.; BIONDO, V. - Uma análise descritivo-comparativa de duas versões para o português brasileiro da obra Death of a Salesman

último trecho, por ser ápice de toda a obra; portanto, analisaremos como tal cena foi interpretada por ambos os tradutores.

Para facilitar nossa análise, trataremos, a partir de agora, os textos como A, B e O, sendo que A se refere à tradução de José Rubens Siqueira, B se refere à tradução de Flávio Rangel e $\mathrm{O}$ se refere ao texto original de Arthur Miller.

\section{Análise}

\begin{tabular}{|c|c|c|}
\hline Título original & $\begin{array}{c}\text { Tradução José Rubens } \\
\text { Siqueira }\end{array}$ & Tradução Flávio Rangel \\
\hline Death of a Salesman & $\begin{array}{c}\text { A Morte de um Caixeiro- } \\
\text { Viajante }\end{array}$ & A Morte do Caixeiro Viajante \\
\hline
\end{tabular}

Tabela 1 - Excerto 1

Para dar início à análise, o primeiro excerto escolhido concerne o título da obra, no qual é encontrada a primeira divergência de tradução. Nota-se aí a ausência de qualquer artigo no inglês antes do substantivo "death", porém em ambas as traduções, foi usado o artigo definido "a". Segundo o que pode ser interpretado, os tradutores colocaram o artigo "a" para dar maior fluência ao título e talvez porque a morte é o ápice de toda a obra; portanto, foi dado um destaque a ela. Apesar do acréscimo dos artigos, ambos fizeram uso da técnica de literalidade.

Ainda se tratando de artigos, em 0 , foi utilizado o artigo "a" em "a salesman" que, segundo o dicionário Oxford, é um artigo indefinido e significa "used before countable or singular nouns referring to people or things that have not already been mentioned" ("usado antes de substantivos contáveis ou no singular referindo-se a pessoas ou coisas que ainda não foram mencionadas anteriormente"). Neste caso, a tradução A se manteve fiel à classe gramatical 
ZACARIN, M. C. N.; RADIGHIERI, V. F.; BIONDO, V. - Uma análise descritivo-comparativa de duas versões para o português brasileiro da obra Death of a Salesman

de 0 , fazendo uso de um artigo indefinido, "um", numa opção pela literalidade, ao passo que na tradução $B$, foi feita uma troca pelo artigo definido "o", visto na aglutinação de "de + o", fazendo, desse modo, uso da técnica de transposição. Tal detalhe provoca uma diferença sutil de significado, pois o artigo indefinido "um" quer dizer que se trata de uma pessoa qualquer, um caixeiro-viajante qualquer, já o artigo definido "o", como o próprio nome diz, define, especifica uma pessoa, o caixeiro-viajante, e, no decorrer do livro, percebemos que o caixeiro-viajante do qual a história é contada, Willy Loman, é um caixeiro qualquer, sem nada de especial ou importante. Uma última diferença observada é a grafia da profissão "caixeiroviajante": na tradução $A$, a palavra é grafada com hífen e na tradução $B$, sem hífen. Tal termo, segundo Ernani \& Nicola (1996), possui obrigatoriamente o uso do hífen, como afirmado a seguir:

como regra geral, o Formulário Ortográfico determina que "só se ligam por hífen os elementos das palavras compostas em que se mantém a noção de composição, isto é, os elementos das palavras compostas que mantêm a sua independência fonética, conservando cada um a sua própria acentuação, porém formando, o conjunto, perfeita unidade de sentido" (ERNANI \& NICOLA 1996: 93).

Sendo assim, pode-se deduzir que a falta de hífen na tradução B se dá talvez por uma questão de estética da diagramação, uma vez que tal ausência só ocorre na capa do livro, ou por alguma falha de digitação ou impressão. Contudo, apesar dessa sutil diferença, ambos se utilizam da literalidade.

A primeira cena analisada (ATO I, p. 22, fala de Biff) se passa no quarto do personagem, em uma conversa com seu irmão Happy, em que ele desabafa sobre suas tentativas de trabalhos frustradas e expõe sua opinião a respeito do trabalho na cidade grande (Tabela 2). Como focalizaremos vários trechos curtos dentro deste excerto maior, reproduziremos cada trecho antes de cada discussão para facilitar a leitura. 
ZACARIN, M. C. N.; RADIGHIERI, V. F.; BIONDO, V. - Uma análise descritivo-comparativa de duas versões para o português brasileiro da obra Death of a Salesman

\begin{tabular}{|c|c|c|}
\hline Trecho original & $\begin{array}{c}\text { Tradução José Rubens } \\
\text { Siqueira }\end{array}$ & Tradução Flávio Rangel \\
\hline $\begin{array}{l}\text { Well, I spent six or } \\
\text { seven years after high } \\
\text { school trying to work } \\
\text { myself up. Shipping } \\
\text { clerk, salesman, } \\
\text { business of one kind } \\
\text { or another. And it's } \\
\text { measly manner of } \\
\text { existence. To get on } \\
\text { that subway on the } \\
\text { hot mornings in } \\
\text { summer. To devote } \\
\text { your whole life to } \\
\text { keeping stock, or } \\
\text { making phone calls or } \\
\text { selling or buying. To } \\
\text { suffer fifty weeks of } \\
\text { the year for the sake } \\
\text { of a two-week } \\
\text { vacation, when all } \\
\text { you really desire is to } \\
\text { be outdoors, with } \\
\text { your shirt off. And } \\
\text { always to have to get } \\
\text { ahead of the next } \\
\text { fella. And still - that's } \\
\text { how you build a } \\
\text { future. }\end{array}$ & $\begin{array}{l}\text { Bom, eu passei uns seis, } \\
\text { sete anos depois da escola } \\
\text { tentando trabalhar por } \\
\text { minha conta. Com } \\
\text { expedição, com vendas, } \\
\text { com uma coisa e outra. E é } \\
\text { um jeito de viver miserável. } \\
\text { Pegar o metrô de manhã no } \\
\text { calor do verão. Botar sua } \\
\text { vida inteira em controle de } \\
\text { estoque, fazer telefonema, } \\
\text { comprar, vender. Sofrer } \\
\text { cinquenta semanas por ano } \\
\text { em troca de duas semanas } \\
\text { de férias, quando o que } \\
\text { você mais quer de verdade } \\
\text { é sair fora, tirar a camisa. E } \\
\text { ter que estar sempre } \\
\text { passando na frente dos } \\
\text { outros. E é assim... assim } \\
\text { que se constrói o futuro. }\end{array}$ & $\begin{array}{l}\text { Depois que eu saí do } \\
\text { ginásio, eu passei seis ou } \\
\text { sete anos procurando } \\
\text { encontrar a mim mesmo. } \\
\text { Fui balconista, caixeiro- } \\
\text { viajante, vendedor disso } \\
\text { ou daquilo. E é uma vida } \\
\text { sem sentido. Entrar naquele } \\
\text { metrô num dia de sol. } \\
\text { Devotar uma vida inteira a } \\
\text { verificar o estoque, } \\
\text { telefonar, vender ou } \\
\text { comprar. Sofrer durante } \\
\text { onze meses e meio num ano } \\
\text { pra depois ter quinze dias } \\
\text { de férias, quando tudo que } \\
\text { você deseja é viver ao ar } \\
\text { livre, sem camisa. E ser } \\
\text { obrigado a passar para trás } \\
\text { o sujeito que está na tua } \\
\text { frente. E é assim que se } \\
\text { constrói um futuro. }\end{array}$ \\
\hline
\end{tabular}

Tabela 2 - Excerto 2

O verbete "work up" (phrasal verb) é definido como "to develop or improve something with some effort; to make somebody/yourself reach a state of great excitement, anger, etc." (“desenvolver ou melhorar alguma coisa com algum esforço; fazer alguém/você mesmo alcançar um estado de grande excitação, raiva, etc.”).

Em análise o phrasal verb traduzido, “work up”, notamos que o trecho A é uma tradução literal etimológica, se atentando ao sentido unicamente desse phrasal verb; o procedimento é definido por Barbosa como: 
ZACARIN, M. C. N.; RADIGHIERI, V. F.; BIONDO, V. - Uma análise descritivo-comparativa de duas versões para o português brasileiro da obra Death of a Salesman

A tradução literal corresponde à ideia mais difundida a respeito da tradução [...]. Aubert (1987: 15) considera a tradução literal como "aquela que se mantém uma fidelidade semântica estrita, adequando porém a morfossintaxe às normas gramaticais da $\mathrm{LT}^{1}$ ”. (BARBOSA 1990: 65).

No trecho B, é feita uma tradução de natureza equivalente, predominando a semântica dentro da intenção da fala do personagem. Para Barbosa (1990: 67), “a equivalência consiste em substituir um segmento do texto da LO2 por um outro segmento da LT que não o traduz literalmente, mas que the é funcionalmente equivalente".

Pelo contexto geral da obra, é possível depreender que o sentido real que o autor parece dar é o de “encontrar-se a si mesmo", empregado no trecho $B$, pois o personagem Biff arruma vários empregos diferentes para tentar encontrar aquele com o qual mais se identifica, e não no sentido de trabalhar por conta própria, como no trecho A, pois, ao longo da história, podemos notar que a família Loman não tinha condições de abrir vários negócios para Biff até ele achar o que queria.

Dando sequência à análise do excerto, em relação às profissões citadas pelo personagem, a primeira delas é "shipping clerk". Segundo o Oxford Advanced Learner's Dictionary, "shipping clerk" é "a atividade de carregar pessoas ou bens de um lugar para outro de barco" ("the activity of carrying people or goods from one place to another by ship”). Após uma breve pesquisa, constatamos que não há um termo equivalente exato na língua portuguesa para essa profissão. Poderia ser algo como "despachante", ou seja, aquele que expede mercadorias. Assim, notamos então, que ambos os tradutores decidiram omitir um dos termos, priorizando o significado de apenas um deles. No trecho A, o termo escolhido foi "shipping", que literalmente significa "embarque, despacho, remessa" (MICHAELIS c2016), enquanto que no trecho $B$, o termo escolhido foi o segundo, “clerk", que

\footnotetext{
${ }^{1} \mathrm{LT}$ - Língua traduzida.

2 LO - Língua original.
} 
ZACARIN, M. C. N.; RADIGHIERI, V. F.; BIONDO, V. - Uma análise descritivo-comparativa de duas versões para o português brasileiro da obra Death of a Salesman

literalmente significa "escriturário, escrevente, copista, balconista" (MICHAELIS c2016). Portanto, nenhum dos dois tradutores optou por traduzir a expressão "shipping clerk" por completo. Para a tradução total da mesma, seria necessário fazer o uso da técnica de explicitação, no sentido de explicar o trabalho realizado em tal profissão que, segundo o dicionário online The Free Dictionary, significa:

Aquele que é empregado para preparar, empacotar, receber ou registrar embarques de bens; (Profissões) uma pessoa empregada por uma empresa para arrumar, receber, registrar e enviar carregamentos de bens; um balconista que atende ao empacotamento, despache, etc., de carregamentos. ${ }^{3}$ (tradução nossa)

Barbosa descreve os procedimentos de omissão e explicitação como:

a omissão consiste em omitir elementos do $\mathrm{TLO}^{4}$ que, do ponto de vista da LT, são desnecessários ou excessivamente repetitivos. [...]. $\mathrm{Na}$ tradução do inglês para o português seria usado, para o mesmo caso, o procedimento inverso, a explicitação do pronome, pois sua presença é obrigatória em inglês. (BARBOSA 1990: 68)

A segunda profissão citada pelo personagem Biff é "salesman", significando "a man or a woman whose job is to sell goods, for example, in a shop/store" ("um homem ou uma mulher cujo trabalho é vender bens, por exemplo, em uma loja") que, traduzida literalmente, significa "agente de vendas, vendedor, representante de vendas" (MICHAELIS c2016). Segundo o mesmo dicionário, "caixeiro-viajante" significa "indivíduo que viaja por conta de uma empresa ou por conta própria para divulgar e vender produtos; cometa, viajante". Podemos então deduzir, com base nessas definições em português, que o significado de caixeiro-viajante foi alterado ao longo do tempo. No trecho A, o tradutor faz uso da transposição:

\footnotetext{
3 "One who is employed to prepare, pack, receive, or record shipments of goods; (Professions) a person employed by a company to arrange, receive, record, and send shipments of goods; a clerk who attends to the packing, dispatching, etc., of shipments." ${ }^{4}$ TLO - Texto da língua original.
} 
ZACARIN, M. C. N.; RADIGHIERI, V. F.; BIONDO, V. - Uma análise descritivo-comparativa de duas versões para o português brasileiro da obra Death of a Salesman

Este procedimento é definido por Vinay e Darbelnet (1977), Vàzquez-Ayora (1977), Newmark (1988) e Catford (1965). A transposição ocorre quando um significado expresso no texto original por um significante de uma categoria gramatical passa a ser expresso no texto traduzido por um significante de outra categoria gramatical, sem que seja alterada a mensagem original. (BARBOSA 1990: 28)

Ao mencionar a atividade exercida pelo caixeiro-viajante, e não a profissão em si, para manter o padrão sintático de sua frase na tradução. No trecho B, a palavra é traduzida literalmente como “caixeiro-viajante". Na terceira profissão, a palavra "business", que significa "the activity of making, buying, selling or supplying goods or services for money" ("a atividade de fazer, comprar, vender ou fornecer bens ou serviços por dinheiro"), foi omitida no trecho A, para manter a ordem da frase de acordo com o que ele já havia escrito, mantendo a mesma classe gramatical e com a mesma preposição, para uma melhor sonoridade da frase. Já no trecho $B$, foi feito uso da transposição, substituindo a palavra "business", que significa literalmente "negócio, atividade comercial, comércio" (MICHAELIS c2016), para o termo “vendedor", fazendo alusão à profissão exercida por Biff, e não à atividade, pois, assim como no trecho $A$, houve a manutenção da sequência de palavras na mesma ordem gramatical, para proporcionar uma leitura mais fluída do texto, visto que também é usado o nome das profissões anteriormente na frase.

\begin{tabular}{|c|c|c|}
\hline Trecho original & $\begin{array}{c}\text { Tradução José Rubens } \\
\text { Siqueira (Trecho A) }\end{array}$ & $\begin{array}{c}\text { Tradução Flávio Rangel } \\
\text { (Trecho B) }\end{array}$ \\
\hline
\end{tabular}


ZACARIN, M. C. N.; RADIGHIERI, V. F.; BIONDO, V. - Uma análise descritivo-comparativa de duas versões para o português brasileiro da obra Death of a Salesman

\begin{tabular}{|c|c|c|}
\hline $\begin{array}{l}\text { And it's measly manner } \\
\text { of existence. To get on } \\
\text { that subway on the hot } \\
\text { mornings in summer. } \\
\text { To devote your whole } \\
\text { life to keeping stock, } \\
\text { or making phone calls } \\
\text { or selling or buying. To } \\
\text { suffer fifty weeks of } \\
\text { the year for the sake } \\
\text { of a two-week } \\
\text { vacation, when all you } \\
\text { really desire is to be } \\
\text { outdoors, with your } \\
\text { shirt off. And always to } \\
\text { have to get ahead of } \\
\text { the next fella. And still } \\
\text { - that's how you build } \\
\text { a future. }\end{array}$ & $\begin{array}{l}\text { E é um jeito de viver } \\
\text { miserável. Pegar o metrô de } \\
\text { manhã no calor do verão. } \\
\text { Botar sua vida inteira em } \\
\text { controle de estoque, fazer } \\
\text { telefonema, comprar, } \\
\text { vender. Sofrer cinquenta } \\
\text { semanas por ano em troca } \\
\text { de duas semanas de férias, } \\
\text { quando o que você mais } \\
\text { quer de verdade é sair fora, } \\
\text { tirar a camisa. E ter que } \\
\text { estar sempre passando na } \\
\text { frente dos outros. E é } \\
\text { assim... assim que se } \\
\text { constrói o futuro. }\end{array}$ & $\begin{array}{l}\text { E é uma vida sem sentido. } \\
\text { Entrar naquele metrô num } \\
\text { dia de sol. Devotar uma } \\
\text { vida inteira a verificar o } \\
\text { estoque, telefonar, vender } \\
\text { ou comprar. Sofrer } \\
\text { durante onze meses e } \\
\text { meio num ano pra depois } \\
\text { ter quinze dias de férias, } \\
\text { quando tudo que você } \\
\text { deseja é viver ao ar livre, } \\
\text { sem camisa. E ser obrigado } \\
\text { a passar para trás o sujeito } \\
\text { que está na tua frente. E é } \\
\text { assim que se constrói um } \\
\text { futuro. }\end{array}$ \\
\hline
\end{tabular}

Tabela 3 - Excerto 3

Seguindo para a análise do próximo trecho destacado, "to devote your whole life to keeping stock" ("devotar toda a sua vida em manter o estoque"), há a frase de maior divergência, tanto no sentido sintático, quanto no semântico. No trecho A, fica evidente que o tradutor fez uso de uma maior poética no seu texto, através da técnica de modulação, a qual

consiste em reproduzir a mensagem da TLO no $\mathrm{TLT}^{5}$, mas sob um ponto de vista diverso, o que reflete uma diferença no modo como as línguas interpretam a experiência do real [...]. Este procedimento é definido por Vinay e Darbelnet (1977 q.v. 2.1, p. 28), Vázquez-Ayora (1977) e Newmark $(1981,1988)$ (BARBOSA, 1990: 67).

Ao traduzir tal frase como "botar sua vida inteira em controle de estoque", a qual nos dá a ideia de que o personagem vive para trabalhar, que o trabalho o controla o tempo todo, o que ilustra de forma clara a ideia que o personagem faz a respeito do trabalho na cidade grande. Já no trecho $B$, “devotar uma vida inteira a verificar o estoque", notamos que o tradutor é bem mais literal

\footnotetext{
${ }^{5}$ TLT - Texto da língua traduzida.
} 
ZACARIN, M. C. N.; RADIGHIERI, V. F.; BIONDO, V. - Uma análise descritivo-comparativa de duas versões para o português brasileiro da obra Death of a Salesman

do que o primeiro, por tratar os termos priorizando o diálogo e a fala original, dando maior dramaticidade à fala do personagem.

No último trecho destacado, "to suffer fifty weeks of the year for the sake of a two-week vacation" ("sofrer cinquenta semanas do ano com o intento de duas semanas de férias”), o personagem fala sobre sua jornada de trabalho, contando-a em semanas como é usual nos Estados Unidos. Na tradução A, foi mantida a mesma estrutura, optando pela literalidade, deixando o tempo em semanas, o que não é comum falarmos no Brasil; enquanto na tradução $B$, o tradutor domesticou o texto, convertendo o tempo de semanas para meses, de forma que o texto fique mais próximo da cultura de chegada, no caso, a cultura brasileira, fazendo uso, portanto, da técnica de equivalência por mencionar a mesma informação, porém de maneira mais próxima ao leitor brasileiro.

O próximo excerto a ser analisado vem de uma cena do Ato II (p. 131), que mostra um diálogo entre Willy Loman e seu filho Biff e constitui a cena mais marcante da peça, onde ocorre todo o desfecho da trama e a ocasião da tragédia final.

\begin{tabular}{|c|c|c|}
\hline Trecho original & $\begin{array}{c}\text { Tradução José Rubens } \\
\text { Siqueira (Trecho A) }\end{array}$ & $\begin{array}{c}\text { Tradução Flávio Rangel } \\
\text { (Trecho B) }\end{array}$ \\
\hline $\begin{array}{l}\text { WILLY: And whose fault } \\
\text { is that? } \\
\text { BIFF: And I never got } \\
\text { anywhere because you } \\
\text { blew me so full of hot } \\
\text { air I could never stand } \\
\text { taking orders from } \\
\text { anybody! That's whose } \\
\text { fault it its! } \\
\text { WILLY: I hear that! } \\
\text { LINDA: Don't, Biff! } \\
\text { BIFF: It's goddam time } \\
\text { you heard that! I had } \\
\text { to be boss big shot in } \\
\text { two weeks, and I'm } \\
\text { through with it! }\end{array}$ & $\begin{array}{l}\text { WILLY: E de quem é a culpa? } \\
\text { BIFF: Eu nunca cheguei a } \\
\text { lugar nenhum porque o } \\
\text { senhor sempre me elogiou } \\
\text { tanto que eu não consegui } \\
\text { nunca aceitar ordens de } \\
\text { ninguém! É aí que está a } \\
\text { culpa! } \\
\text { WILLY: Entendi! } \\
\text { LINDA: Não faça isso, Biff! } \\
\text { BIFF: Está na hora do } \\
\text { senhor escutar! Eu tinha } \\
\text { que ser chefe, tinha que ser } \\
\text { o maioral em quinze dias! } \\
\text { Para mim, chega disso! } \\
\text { WILLY: Então morra! }\end{array}$ & $\begin{array}{l}\text { WILLY: E de quem é a } \\
\text { culpa? } \\
\text { BIFF: Eu nunca consegui } \\
\text { nada na vida porque você } \\
\text { me encheu a cabeça de } \\
\text { vento e eu jamais suportei } \\
\text { receber ordens de } \\
\text { ninguém! Aí está de quem } \\
\text { é a culpa! } \\
\text { WILLY: E eu ainda tenho } \\
\text { que ouvir isso! } \\
\text { LINDA: Chega, Biff! } \\
\text { BIFF: Já está na hora de } \\
\text { ouvir isso! Eu tinha que } \\
\text { ser o patrão e o dono por } \\
\text { quinze dias, e estou cheio }\end{array}$ \\
\hline
\end{tabular}


ZACARIN, M. C. N.; RADIGHIERI, V. F.; BIONDO, V. - Uma análise descritivo-comparativa de duas versões para o português brasileiro da obra Death of a Salesman

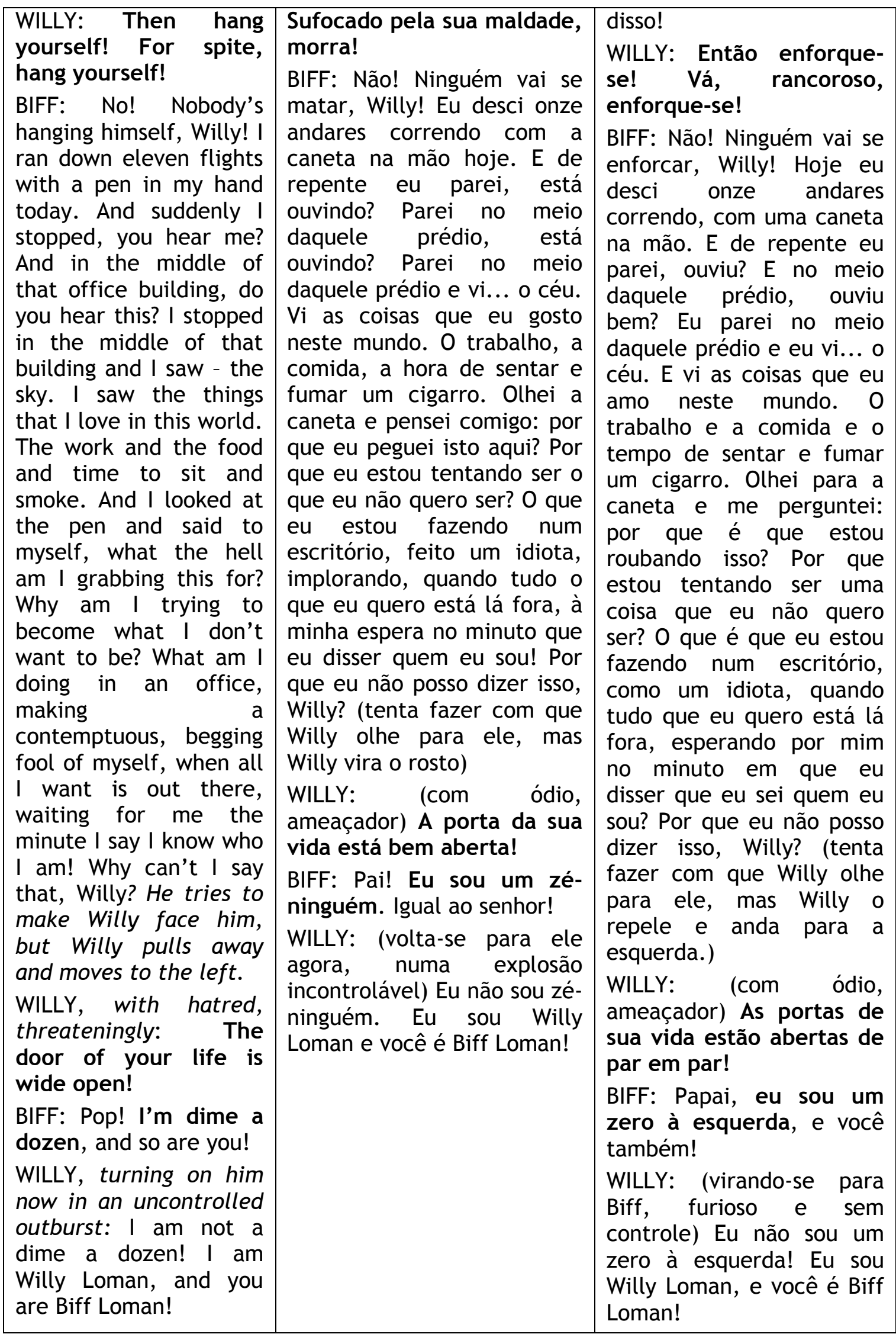


ZACARIN, M. C. N.; RADIGHIERI, V. F.; BIONDO, V. - Uma análise descritivo-comparativa de duas versões para o português brasileiro da obra Death of a Salesman

Tabela 4 - Excerto 4

Esse excerto nos oferece várias oportunidades para análise comparativa. O primeiro trecho a se destacar é "I never got anywhere". Segundo o Oxford Advanced Learner's Dictionary, “to get anywhere” é uma expressão idiomática que significa "to make progress”, ou seja, “progredir”. Em A, ao usar "eu nunca cheguei a lugar algum", o tradutor optou por fazer uma tradução mais literal, se prendendo mais ao texto original. No entanto, em $B$, “eu nunca consegui nada na vida”, houve uma modulação na frase, que possui o mesmo sentido que o original, porém carregado de uma maior dramaticidade na fala.

O trecho selecionado em seguida, "you blew me so full of hot air", de acordo com o dicionário online The Free Dictionary, constitui outra expressão idiomática de uso informal definida como "if something that someone says is just hot air, it is not sincere and will have no practical results; empty, exaggerated talk; boasting, lying, nonsense" ("se algo que alguém diz é apenas 'hot air', não é sincero e não terá resultados práticos; vazio, conversa exagerada; vanglória, mentira, bobagem”). A partir desse contexto, é possível depreender que se trata de uma metáfora que significa "inflar o ego (de algo/alguém)", equivalente à expressão "encher a bola" do português brasileiro. Com isso, podemos perceber que a tradução B captou melhor essa mensagem ao dizer "você me encheu a cabeça de vento". É importante observar que o diálogo entre pai e filho neste ponto marca o ápice de uma relação problemática, momento este que o filho aproveita para pôr para fora todas as mágoas guardadas por tanto tempo em relação ao pai. Willy Loman sempre tentou fazer com que o filho acreditasse que ele era mais e melhor do que a realidade mostrava. Assim, a tradução $B$ traz toda a conotação negativa que a expressão em inglês demonstra. Já a expressão utilizada na tradução $A$, “o senhor sempre me elogiou tanto", tem um significado próximo, porém menos enfático, menos dramático, que é o que a cena pede, apesar de também ter feito uso da técnica de equivalência. 
ZACARIN, M. C. N.; RADIGHIERI, V. F.; BIONDO, V. - Uma análise descritivo-comparativa de duas versões para o português brasileiro da obra Death of a Salesman

\begin{tabular}{|c|c|c|}
\hline Trecho original & $\begin{array}{l}\text { Tradução José Rubens } \\
\text { Siqueira (Trecho A) }\end{array}$ & $\begin{array}{c}\text { Tradução Flávio Rangel } \\
\text { (Trecho B) }\end{array}$ \\
\hline $\begin{array}{l}\text { BIFF: It's goddam } \\
\text { time you heard that! } \\
\text { I had to be boss big } \\
\text { shot in two weeks, } \\
\text { and I'm through with }\end{array}$ & $\begin{array}{l}\text { BIFF: Está na hora do } \\
\text { senhor escutar! Eu tinha } \\
\text { que ser chefe, tinha que ser } \\
\text { o maioral em quinze dias! } \\
\text { Para mim, chega disso! }\end{array}$ & $\begin{array}{l}\text { BIFF: Já está na hora de } \\
\text { ouvir isso! Eu tinha que ser } \\
\text { o patrão e o dono por } \\
\text { quinze dias, e estou cheio } \\
\text { disso! }\end{array}$ \\
\hline $\begin{array}{l}\text { it! } \\
\text { WILLY: Then hang } \\
\text { yourself! For spite, } \\
\text { hang yourself! }\end{array}$ & $\begin{array}{lcr}\text { WILLY: } & \text { Então } & \text { morra! } \\
\text { Sufocado } & \text { pela } & \text { sua } \\
\text { maldade, } & \text { morra! } & \end{array}$ & $\begin{array}{l}\text { WILLY: Então enforque-se! } \\
\text { Vá, rancoroso, enforque- } \\
\text { se! }\end{array}$ \\
\hline
\end{tabular}

Tabela 5 - Excerto 5

Passemos, agora, à análise do trecho "It's goddam time you heard that!". Nele, focalizamos a palavra "goddamn", definida como "a slang, a swear word that many people find offensive, used to show that you are angry or annoyed" ("uma gíria, uma palavra de baixo calão que muitas pessoas acham ofensiva, usada para mostrar que você está nervoso ou irritado") e traduzida no dicionário Michaelis (c2016) como "maldito", em português. Contudo, podemos notar que em nenhuma das traduções a palavra foi utilizada, ou qualquer outra de sentido similar, havendo, portanto, uma omissão de tal expressão tanto na tradução $A$ quanto na tradução $B$. Esta omissão, até certo ponto, parece tirar a dramaticidade da cena e o peso das palavras do filho dirigidas ao pai.

No trecho seguinte, "then hang yourself! For spite, hang yourself!", focalizamos o verbo "to hang", definido como "to kill somebody usually as punishment, by tying a rope around their neck and allowing them to drop; to be killed in this way" ("matar alguém, geralmente como punição, amarrando uma corda ao redor do seu pescoço e permitindo que ele caia; ser assassinado desta forma”). Na tradução A, o tradutor utiliza a técnica da modulação, pois o significado literal da palavra "hang" é "enforcar(-se), ser enforcado" (Michaelis c2016), porém, em vez de usar tal verbo, foi utilizado outro de sentido similar, mais geral, no caso, “morrer”. Na tradução B, foi feito o uso 
ZACARIN, M. C. N.; RADIGHIERI, V. F.; BIONDO, V. - Uma análise descritivo-comparativa de duas versões para o português brasileiro da obra Death of a Salesman

da literalidade, uma vez que "hang" significa "enforcar", como já foi dito acima. Ambos foram opostos nos procedimentos tradutórios, porém segundo a nossa interpretação, Willy estava ordenando a Biff que se matasse, sendo assim, nenhuma das traduções expressou exatamente esse sentido.

No mesmo trecho, a tradução da expressão "for spite" também é digna de nota. No dicionário, esta expressão vem definida como um substantivo, "a feeling of wanting to hurt or upset somebody - synonym: malice" ("uma sensação de querer machucar ou chatear alguém - sinônimo: malícia”). Na tradução A, "sufocado pela sua maldade", é difícil definir qual o processo tradutório utilizado; porém, o que mais se aproxima é a modulação, na tentativa de expressar o sentimento do personagem na fala em 0 , além de dar uma maior dramaticidade ao texto. $\mathrm{Na}$ tradução $\mathrm{B}$, é possível identificar $\mathrm{O}$ processo de transposição, pois nela o substantivo "spite", o qual significa "rancor" (MICHAELIS C2016), foi trocado pelo adjetivo referente a ele, no caso, "rancoroso".

Seguiremos, agora, para as análises dos últimos trechos destacados.

\begin{tabular}{|c|c|c|}
\hline Trecho original & $\begin{array}{c}\text { Tradução José Rubens } \\
\text { Siqueira (Trecho A) }\end{array}$ & $\begin{array}{c}\text { Tradução Flávio Rangel } \\
\text { (Trecho B) }\end{array}$ \\
\hline $\begin{array}{l}\text { WILLY, with hatred, } \\
\text { threateningly: The } \\
\text { door of your life is } \\
\text { wide open! } \\
\text { BIFF: Pop! I'm dime a } \\
\text { dozen, and so are you! } \\
\text { WILLY, turning on him } \\
\text { now in an uncontrolled } \\
\text { outburst: I am not a } \\
\text { dime a dozen! I am } \\
\text { Willy Loman, and you } \\
\text { are Biff Loman! }\end{array}$ & $\begin{array}{l}\text { WILLY: (com ódio, } \\
\text { ameaçador) A porta da sua } \\
\text { vida está bem aberta! } \\
\text { BIFF: Pai! Eu sou um zé- } \\
\text { ninguém. Igual ao senhor! } \\
\text { WILLY: (volta-se para ele } \\
\text { agora, numa explosão } \\
\text { incontrolável) Eu não sou } \\
\text { zé-ninguém. Eu sou Willy } \\
\text { Loman e você é Biff Loman! }\end{array}$ & $\begin{array}{l}\text { WILLY: (com ódio, } \\
\text { ameaçador) As portas } \\
\text { de sua vida estão } \\
\text { abertas de par em par! } \\
\text { BIFF: Papai, eu sou um } \\
\text { zero à esquerda, e } \\
\text { você também! } \\
\text { WILLY: (virando-se para } \\
\text { Biff, furioso e sem } \\
\text { controle) Eu não sou um } \\
\text { zero à esquerda! Eu sou } \\
\text { Willy Loman, e você é } \\
\text { Biff Loman! }\end{array}$ \\
\hline
\end{tabular}

Tabela 6 - Excerto 6 
ZACARIN, M. C. N.; RADIGHIERI, V. F.; BIONDO, V. - Uma análise descritivo-comparativa de duas versões para o português brasileiro da obra Death of a Salesman

No primeiro trecho destacado, "the door of your life is wide open!", "wide" é definido como "as far or fully as possible. Ex: the door was wide open" ("tão distante ou completo quanto possível. Ex.: a porta estava totalmente aberta"). É possível observar que na tradução A, "a porta da sua vida está bem aberta!", foi utilizado o processo de palavra-por-palavra, o qual é cenceituado por Barbosa como:

enquanto procedimento tradutório, é definida por Catford (1965), Newmark (1988) e Aubert (1987). É caracterizada aqui segundo a definição de Aubert (1987:15): a tradução em que determinado segmento textual (palavra, frase, oração) é expresso na LT mantendo-se as mesmas categorias numa mesma ordem sintática, utilizando vocábulos cujo semanticismo seja (aproximativamente) idêntico ao dos vocábulos correspondentes no TLO. (BARBOSA 1990: 28)

Já na tradução B, "as portas de sua vida estão abertas de par em par!", segundo a nossa análise, dentre os procedimentos descritos por Barbosa, o que melhor parece se encaixar é a equivalência, uma vez que a palavra "wide" não é traduzida literalmente - como na tradução A, por exemplo -, mas com uma expressão que possui a mesma ideia. Ambas as traduções estão adequadas ao trecho 0 , porém a tradução $B$, ao fazer uso de uma expressão datada e pouco usual (de par em par), causa certa estranheza ao leitor na atualidade.

No último trecho destacado, analisamos a expressão "dime a dozen", expressão idiomática definida como "very common and therefore not valuable" ("muito comum e, portanto, sem valor"). Podemos observar que tanto a tradução $A$, quanto a tradução $B$ se mostram adequadas em relação a 0 , pois tal expressão significa "algo que vale muito pouco ou nada"; no caso da tradução A, a expressão escolhida foi "zé-ninguém", enquanto na $B, a$ escolhida foi "zero à esquerda", ambas tendo o significado que a original quer expressar, além de serem bem conhecidas e típicas da fala coloquial. Nas duas traduções, o procedimento técnico utilizado foi a equivalência. 
ZACARIN, M. C. N.; RADIGHIERI, V. F.; BIONDO, V. - Uma análise descritivo-comparativa de duas versões para o português brasileiro da obra Death of a Salesman

\section{Considerações finais}

Este trabalho analisou excertos de duas traduções para o português brasileiro da peça Death of a Salesman, por José Rubens Siqueira e Flávio Rangel, publicadas com trinta e três anos de diferença entre elas, a fim de verificar os aspectos linguísticos e culturais e a forma como estes foram empregados no texto traduzido, com o propósito de identificar as disparidades ocorridas em trechos selecionados.

Em vista das análises feitas, é possível afirmar que ambas as traduções se mostraram bastante adequadas em vista do original. No entanto, ambas também apresentaram discrepâncias no decorrer do texto, principalmente em relação a algumas expressões idiomáticas. Em alguns momentos, notou-se que um tradutor captou melhor a ideia expressa no original, porém isso não se manteve no decorrer dos trechos analisados. Foi possível observar, em determinados momentos, um tradutor foi mais poético, deixando-se levar mais pela escrita literária, e outro mais dramático, direcionado ao texto como script para ser encenado.

Durante a análise, foram utilizados os procedimentos técnicos definidos por Barbosa (1990) para classificar as escolhas tradutórias de cada um. Dentre eles, observa-se um maior uso da tradução literal, ocorrida onze vezes dentre os trechos analisados; o segundo procedimento mais utilizado foi a equivalência, com sete ocorrências; o procedimento que aparece em terceiro lugar é a omissão, com cinco ocorrências; em quarto lugar foram a transposição e a modulação, ambas com quatro ocorrências cada, e, por fim, a tradução palavra-por-palavra com uma única ocorrência. Foram identificados seis dos treze processos definidos por Barbosa, bem como a tradução identificadora descrita por Paulo Rónai. 
ZACARIN, M. C. N.; RADIGHIERI, V. F.; BIONDO, V. - Uma análise descritivo-comparativa de duas versões para o português brasileiro da obra Death of a Salesman

Como citado previamente na teoria deste estudo, não apenas o conhecimento do par de línguas trabalhado é necessário, mas sua capacidade individual, pois cada pessoa possui sua própria bagagem de conhecimento e visão de mundo, que acabam influenciando escolhas. Ou seja, cada tradutor possui sua própria interpretação em relação ao nível de linguagem e, apesar de não serem observados muitos equívocos nos trechos analisados, há termos que são mais adequados do que outros em determinados momentos, conforme esse estudo procurou mostrar.

Constatou-se que apesar das traduções terem sido feitas em épocas diferentes e publicadas por editoras e tradutores distintos, elas apresentaram os mesmos valores, e o que as diferencia são meros detalhes, que não influenciam significativamente no entendimento geral da obra.

\section{Referências bibliográficas}

ANAUATE, Gisela. "A tradução é uma ponte entre duas culturas". In: Revista Época, c2007. Disponível em: <http://revistaepoca.globo.com/Revista/Epoca/0, EDG798095856,00.html>. Acesso em: 14 maio 2016.

ARrojo, Rosemary. Oficina de Tradução: A teoria na prática. 1. ed. São Paulo: Editora Ática S.A., 1986.

ARTHUR MILleR. Wikipedia, 2016. Disponível em: <https://en.wikipedia.org/wiki/Arthur_Miller>. Acesso em: 21 out. 2016.

ARTHUR MILleR. Wikipédia, 2016. Disponível em: <https://pt.wikipedia.org/wiki/Arthur_Miller>. Acesso em: 21 out. 2016. 
ZACARIN, M. C. N.; RADIGHIERI, V. F.; BIONDO, V. - Uma análise descritivo-comparativa de duas versões para o português brasileiro da obra Death of a Salesman

ARTHUR Miller Biography. Biography, 2016. Disponível em: <http://www.biography.com/people/arthur-miller9408335\#synopsis>. Acesso em: 21 out. 2016.

Arthur Miller's official Website. Arthur Miller, c?. Disponível em: <http://www.arthurmiller.org/>. Acesso em: 22 out. 2016.

Barbosa, Heloisa Gonçalves. Procedimentos técnicos da tradução: uma nova proposta. Campinas: Pontes. 1990.

DeAth of a Salesman. Wikipedia, 2016. Disponível em: <https://en.wikipedia.org/wiki/Death_of_a_Salesman>. Acesso em: 26 out. 2016.

ERNANI \& NICOLA. Guia Prático de Ortografia. 1. ed. São Paulo: Editora Scipione, 1996.

Flávio Nogueira RANGel. Biografias. UOL, c1996-2016. Disponível em: <http://educacao.uol.com.br/biografias/flavio-nogueira-rangel.htm>. Acesso em: 21 out. 2016.

FlÁvIO RANGEL. eBiografia. 7Graus, 2012. Disponível em: <https://www.ebiografia.com/flavio_rangel/>. Acesso em: 21 out. 2016.

GonÇAlVES Filho, Antonio. Morre o dramaturgo Arthur Miller. Senado, 2005. Disponível em: <http://www2.senado.leg.br/bdsf/bitstream/handle/id/305789/notic ia.htm?sequence=1>. Acesso em: 21 out. 2016.

HOT AIR. THE FREE DICTIONARY, c2016. Disponível em: <http://idioms.thefreedictionary.com/hot+air>. Acesso em: 10 nov. 2016.

JosÉ RUBENS SIQUEIRA. Teatropédia, 2011. Disponível em: <http://www.teatropedia.com/wiki/Jos\%C3\%A9_Rubens_Siqueira>. Acesso em: 21 out. 2016. 
ZACARIN, M. C. N.; RADIGHIERI, V. F.; BIONDO, V. - Uma análise descritivo-comparativa de duas versões para o português brasileiro da obra Death of a Salesman

Miller, Arthur. A Morte de um Caixeiro-Viajante e Outras 4 Peças. Tradução de José Rubens Siqueira. São Paulo: Companhia das Letras, 2009. A Morte do Caixeiro Viajante. Tradução de Flávio Rangel. São Paulo: Abril S.A. Cultural e Industrial, 1976.

. Death of a Salesman. 17 ed. New York: Penguin Books, 1976.

OXford AdVAnCed Learner's Dictionary. 8. ed. p. 01, 199, 272, 423, 650, 665, 704, 1351, 1412, 1487, 1761, 1776. Oxford: Oxford University Press, 2010.

Pagano, Adriana. et. al. Traduzir com autonomia: estratégias para o tradutor em formação. 4. ed. São Paulo: Ed. Contexto, 2013.

Pagano, Adriana; Magalhães, Celia Maria; Alves, Fabio. Competência em tradução: cognição e discurso. Belo Horizonte: Humanitas/UFMG, 2005.

RónAl, Paulo. Escola de tradutores. 6. ed. Rio de Janeiro: Nova Fronteira, INL, 1987.

A tradução vivida. 2. ed. Rio de Janeiro: Nova Fronteira, 1981.

SHIPPING CLERK. The Free Dictionary, c2016. Disponível em: <http://www.thefreedictionary.com/shipping+clerk>. Acesso em: 20 out. 2016.

UOL. Michaelis: Dicionário Brasileiro da Língua Portuguesa, c2016. Disponível em: <http://michaelis.uol.com.br/moderno-portugues/>. Acesso em: 15 nov. 2016.

UOL. Michaelis: Moderno Dicionário Inglês, c2016. Disponível em: <http://michaelis.uol.com.br/moderno-ingles/>. Acesso em: 16 nov. 2016.

VenUtI, Lawrence. Escândalos da tradução: por uma ética da diferença. Tradução de Laureano Pelegrin, Lucinéia Marcelino Villela, Marileide Dias Esqueda e Valéria Biondo. Bauru: EDUSC, 2002. 
ZACARIN, M. C. N.; RADIGHIERI, V. F.; BIONDO, V. - Uma análise descritivo-comparativa de duas versões para o português brasileiro da obra Death of a Salesman

Data de submissão: 03/01/2017

Data de aprovação: 03/03/2017

TradTerm, São Paulo, v. 29, Julho/2017, p. 50-79-

www.usp.br/tradterm 